This is an Open Access article, distributed under the terms of the Creative Commons Attribution licence (http://creativecommons.org/licenses/by/4.o/), which permits unrestricted re-use, distribution, and reproduction in any medium, provided the original work is properly cited. doi:10.1017/So 144686X1800020X

\title{
Facilitation of positive social interaction through visual art in dementia: a case study using video-analysis
}

\author{
JUSTINE SCHNEIDER*, SPENCER HAZEL $\dagger$, \\ CHRISTIAN MORGNER + and TOM DENING $\$$
}

\begin{abstract}
The aims of this exploratory study were: to investigate the process of visual art appreciation in a person with dementia, in real time; and to test the feasibility of using videoanalysis as a method to explore this process by and with a person who has minimal verbal expression. Gallery personnel guided a woman with severe dementia around an exhibition. Audio-visual recordings of the interactions were analysed. Patterns were identified, and interpreted in the light of conversation analysis theory and research. Evidence was found of turn-taking vocalisations on the part of the research participant. Her participation in a dialogical process was facilitated by the skilled and empathic gallery personnel in ways that the analysis makes clear. We argue that this supports the inference that successful communicative acts took place, contrary to expectations in the light of the participant's level of disability. We demonstrate in this paper how a woman with minimal speech due to dementia was enabled to engage with visual art through the facilitation of an expert guide, attuned to her needs. This is a novel example of a person-centred approach, because it takes place outside the context of caring, which is the typical setting for examining person-centred ways of relating to individuals with dementia.
\end{abstract}

KEY WORDS - dementia, video, conversation analysis, art gallery, communication, case study, person-centred care.

\section{Introduction}

The purpose of this study was to explore the process of visual art appreciation in a person with advanced dementia. As survival rates from heart disease and

* School of Sociology \& Social Policy, University of Nottingham, UK.

$\dagger$ School of Education, Communication and Language Sciences, University of Newcastle, UK.

\$ School of Media, Communication and Sociology, University of Leicester, UK.

$\S$ Division of Psychiatry and Applied Psychology, School of Medicine, University of Nottingham, UK. 


\section{Justine Schneider et al.}

cancer improve, more of us are likely to die with some form of dementia, which medical science so far cannot prevent or cure (Etkind et al. 2017). The progressive neurodegeneration of dementia in its latter stages can lead to loss of communication by speech (Wasilewski and Kachaniuk 2016: 96). In the United Kingdom (UK), as elsewhere, policy dictates that the majority of people with dementia shall remain at home for as long as possible (Department of Health 2012), so the incidence of severe dementia in a community context (as compared to hospital or nursing homes) is increasing.

\section{Theoretical framework}

In a seminal paper on Alzheimer's disease, Stephen Sabat and Rom Harré drew a distinction between self ${ }^{1}$ and self ${ }^{2}$ (Sabat and Harré 1992). The former refers to the inalienable identity of a human being, that which cannot be effaced by disability, including the disability arising from dementia. The second type of self is sometimes called 'persona'; we enact self ${ }^{2}$ by behaving in ways that conform to recognisable roles or habits. The capability to perform a given role demands a level of self-awareness, and this can be affected in advanced dementia. The resulting contrast between the two types of self is illustrated by the challenge facing relatives of a person with advanced dementia. That person remains a mother, father or spouse in the sense of self ${ }^{1}$. At the same time, dementia may have deprived them of the ability to express this identity in the relational sense of self ${ }^{2}$. For this role to be enacted, co-operation is required on the part of other people.

One's display of the characteristics of a certain persona enters 'social space' only in so far as it is recognised, responded to and confirmed in the actions of others ... If what one says or does cannot be fitted coherently into a locally acceptable cluster of the types of behaviour that define a self ${ }^{2}$ that person is bound to be treated with reserve or even suspicion. (Sabat and Harré 1992: 446)

Writing at about the same time, Kitwood and Bredin (1992) developed the term 'social malignity' to describe a tendency to regard people with dementia who fail in their social roles with reserve or suspicion. They highlighted the systematic devaluation of people with dementia by those who regard them as having 'hopelessly impaired' identities. Their perspective, like Sabat and Harré, is social constructivist: 'The dementing illness of one person brings to the surface a much larger problematic which challenges our commonsense and customary ways of being' (Kitwood and Bredin 1992: 274). The remedy put forward by Kitwood and Bredin is to facilitate positive social interactions, which affirm not only the essential value of each human being but also their social roles. The way to do this is to promote selfesteem, agency, social confidence and hope in the person with dementia. 
These are the objectives of the approach known as person-centred care, which is held up as the optimal dementia care strategy.

Paradoxically, although most of the research on dementia has been in the context of formal care, with the purpose of improving its effectiveness, formal care settings are, to use Kitwood and Bredin's term, inherently 'socially malign'. In settings like care homes and hospitals, people are routinely disempowered by the hierarchical structure which refers to them as 'patients' or 'residents'. They are placed in a situation where there is risk of being objectified and patronised by strangers who know little about them as individuals. Many of these strangers are employed to accomplish tasks determined by a system beyond the person concerned ('dressing', 'feeding', 'toileting'). The challenge of achieving person-centred care is clearly to overcome the disempowerment, objectification and depersonalisation that can occur in institutional settings. One (rather obvious) way to do so is to change the context in which people with dementia are studied, taking research out of the formal care setting wherever possible. Taking a case study approach, we chose to work with an individual with dementia engaging with visual art in a gallery environment, rather than in a clinical or care setting. That is congruent with the fact that a growing number of people with severe dementia live in their own homes, and are engaged in social activities in their communities in a wide range of ways.

\section{Meaning-making and art}

We adopted an art-world definition of art: works with unique attributes which create new understandings and intervene in the process of meaning-making (Bourdieu 1992; Bürger 1984; Weir 2010). We understand meaning-making as the collaborative co-construction of meaningful behaviour-in this context, with regard to an art exhibition. The meaning of an act or object does not reside in possession of a sole speaker, but is being 'made' in an interactive process, where different actors co-constitute a common understanding. Meaning-making is therefore not just a cognitive act, where 'outside' information is simply received, but it is also a social process that actively engages different actors in the process of meaning-making. Through this process meaning is co-constituted in a sequential and interactive arrangement of different speakers. Importantly, such meaning-making can occur through various media of communication that might be verbal or non-verbal. As a consequence, meaningful behaviour does not necessarily result from oral or written communication, which is the most common understanding, but might also result from an engagement with multi-sensory objects or simply from minor non-verbal behaviour and movements. These forms of meaningful behaviour are easily overlooked. 


\section{Justine Schneider et al.}

For individuals with dementia, this understanding of meaning-making is relevant because it does not depend upon linguistic skills for engagement, but is open to a broad range of behaviours. In dementia, communication becomes problematic when ways of understanding that rely on language tend to break down and shared understandings drift apart. We propose that, in an encounter with art, the process of meaning-making may still remain accessible to an individual whose linguistic skills are impaired. This permits him or her to be an active participant in meaning-making and thereby to co-produce or enact identity in that context.

\section{Previous research}

While there is evidence of people with dementia responding powerfully to visual art (Mittelman and Epstein 2009), previous research has regarded art principally as a means to an end of clinical interest beyond the intervention (Beard 2012; Cowl and Gaugler 2014). Outcomes reported include improving participants' memory (Eekelaar, Camic and Springham 2012) or animation (MacPherson et al. 2009). Camic, Tischler and Pearman (2014) inferred that the caring relationship was improved through mutual engagement with art, while Flatt et al. (2015) found greater social connectedness and self-esteem in participants with dementia following an art intervention.

Among studies of visual art and people with dementia, only a small number have used micro-interactional methods including discourse analysis, conversation analysis (CA) and video-analysis. Dooley, Bailey and McCabe (2015) reviewed observational studies on how patients, companions and health-care professionals communicate. They found 23 studies that gathered data through audio or audio-visual recordings. The analytic methods included thematic analysis and individualised approaches to coding. Only two of the 23 investigations had employed linguistic microanalysis, and these were small, preliminary studies. Saunders (1998) used discourse analysis to explore interactions during neuropsychological assessments $(\mathrm{N}=17)$. Lindholm (2008) and Lindholm and Wray (2011) reported the use of $\mathrm{CA}$ in Finland, with recordings of three professional carers and two patients (Lindholm 2008; Lindholm and Wray 2011). In addition, using video-analysis, Hansebo and Kihlgren (2002) looked at recordings of four staff interacting with nine patients in a Swedish nursing home concerning the use of a structured assessment measure. Most closely resembling the present study, Chatwin (2014) demonstrated analysis of verbal interactions with a single care home resident in the UK using CA. Therefore, there was very little prior research which used similar methods with people with dementia, and none that we could find 
which examined the actual encounter with visual art, as compared to subsequent effects.

\section{Ethical considerations}

It is ethically problematic to film people who lack capacity to give informed consent. Our aim was to apply Dewing's 'process consent model' during the study (Dewing 2007). Dewing's position is that 'capacity is situational, that capacity can be present even after the usual legal threshold has been crossed and that it is often strengthened or even reinvigorated within an enabling and caring relationship' (Dewing 2007: 13). We recruited participants from dementia groups attended by people with dementia accompanied by their spouses. The recruitment of couples ensured the presence of a carer who could give advice about the participation of the individual with dementia. Carers were thus consultees in the terms of the Mental Capacity Act 2005. Their presence at the filming but in a separate room ensured that there was someone close at hand who was attuned to the person with dementia in case of distress or reluctance to participate. We negotiated consent carefully, taking account at the outset of the individual's background, and using a person-centred approach. This appraisal was revisited regularly during the filming for both the person with dementia and their carer. The couples gave consent both to the filming and to the use of the data for research purposes.

\section{Methods}

The purpose of this study was to investigate the process - rather than the outcomes - of visual art appreciation in one individual with severe dementia. We were interested in the actual encounter between a person with dementia and a work of art, in real time. This process we characterise as 'meaning-making'. We also wanted to test the feasibility of using video-analysis as a method to explore meaning-making. An advantage of video recording is that this permits data to be viewed as many times as required to understand it. It can be seen by different people, coded or analysed using different methods, and interrogated using different questions. This may reduce the imposition on research participants and the costs of data collection. The comparative ease with which digital recordings are shared permits research findings to be disseminated widely. Although fine-grained analysis of video recordings is not a new approach, it is only relatively recently that it has gained momentum in social scientific research (Hazel, Mortensen and Rasmussen 2014; Heath and Hindmarsh 2002; Knoblauch 2006), 
displacing audio recordings as the prima facie tool for conducting research into spoken interaction.

The study therefore had two aims: to advance knowledge about using video-analysis for observing people with dementia engaging with visual art; and to generate ideas, including theoretical concepts and hypotheses for further testing, about such engagement. It was conceived as a platform for development of method and theory on visual art and dementia, both of which are discussed below. The impact of the findings might conceivably help to improve the quality of life of people with dementia by sensitising carers, gallery personnel and others to relevant issues. The project was funded by a seedcorn grant from Alzheimer's Research UK and ethical approval was granted by the University of Nottingham School of Sociology \& Social Policy (Reference $5^{8 / 1} 5^{-16 / S}$ ).

\section{Intervention}

The intervention was designed to allay any fears that participants would be required to draw on memory. We introduced people with dementia and their carers to art works that are by definition new: the degree show of Fine Art students. The art students were invited to participate but none took up the opportunity. The gallery personnel received brief (two hours) training on dementia, provided by JS. This consisted of viewing in a small group the video used by The Alzheimer's Society to recruit Dementia Friends, and one more video with medical facts, followed by questions and answers. We recruited people with dementia and their family carers from a local Memory Café. On arrival, each couple was greeted by the research team and several student volunteers. An old-age psychiatrist, (TD) and the principal investigator, JS, explained the process and took consent. The partner's advice as a consultee was taken for all three participants with dementia. At a time when the gallery was closed to the public, we arranged for these people to be individually guided by three gallery staff around the degree show. The family carers who accompanied each individual with dementia were invited to view the exhibition separately, so that they did not interact with their relative during the viewings.

The works themselves included a corner installation with an armchair and occasional table, on which were postcards, pen and a slotted box in which to deposit the cards. On the walls hung portraits of 'mothers', clearly taken in different eras, as evidenced by fashions of hair, make-up and clothes. The invitation to the viewer was to write a postcard to his or her mother. Most of the interaction analysed below took place in relation to this exhibit, which can be seen in Figure 1. 


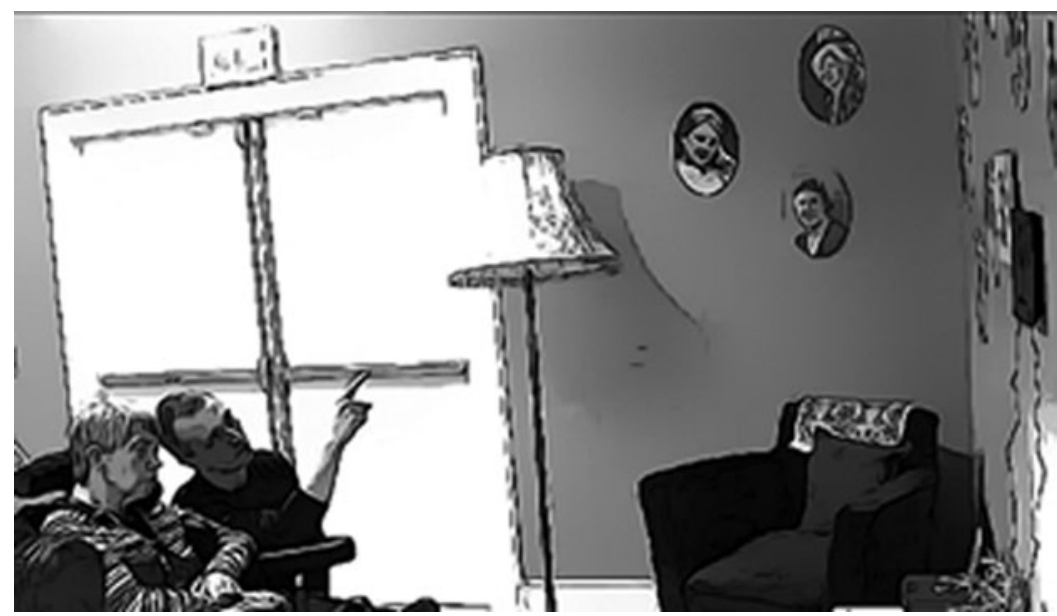

Figure 1. Exhibit and orientation of the viewers.

\section{Participants}

This paper reports on our analysis of data from one woman with dementia, whom we call here Suzan, and two gallery staff. Suzan was brought to the gallery in a wheelchair by her husband. She had practically no speech and spent much of her days dozing in the chair. Her case is of particular interest because of the degree of dementia, and the belief expressed by Suzan's husband that she would not be able to communicate with the guide, nor to engage with the exhibition. Nevertheless, he was motivated to participate in the study because of a long-standing commitment as a carer to support research in dementia. He remained in the adjacent room during the visit, out of sight of Suzan.

\section{Data collection}

Suzan and the gallery staff were recorded during their tours by three strategically positioned camcorders, some supplementary digital audio recordings were made in places where the quality of camcorder sound was poor. We identified the clips with the best sound and clear images, and cleaned up the recordings.

\section{Data analysis}

Video-analysis was then used to understand interaction-based processes through fine-grained analysis (MacPherson et al. 2009). Data were annotated in ELAN, a software program which allowed the researchers to 


\section{$173^{8}$ Justine Schneider et al.}

parse the recordings into discrete phases of the overall activities captured in the gallery. Relevant sections were selected and subsequently exported to the CLAN transcription tool for further treatment (MacWhinney and Wagner 2010). Software tools such as ELAN and CLAN provide researchers with user interfaces that allow the audio or video data to be temporally aligned with the transcription. This facility forms the basis for carrying out video-analysis of interactional events and allows researchers to perform different types of analysis on the data. Additionally, we used these linked software files to extract data segments for further acoustic analysis. This is especially relevant when analysing data generated by participants whose speech is limited to the extent that they are only able to produce non-linguistic vocalisations. Acoustic analysis can unpack what other vocal resources, e.g. pitch, stress and intonation contouring, are deployed in the absence of recognisable linguistic units of talk.

Hansebo and Kihlgren (2002) adopted a phenomenological hermeneutic approach to analysing data from care of nine elderly patients with moderate to severe cognitive impairment. They followed a three-stage process of analysis: naïve understanding, structural analysis (explanation) and comprehensive analysis (interpretation). A similar bottom-up, datadriven set of procedures was followed for our study, albeit here working from a CA perspective. This approach differs from the discourse analytic work of Hansebo and Kihlgren in that it pursues an emic perspective. It focuses on how the participants in the interactions orient to one another and display their understanding of one another's actions. So, whereas Hansebo and Kihlgren (2002) allow themselves to make claims about, for example, the motivations of the participants, from our CA perspective such claims can only be supported when there is evidence in the recorded data of how the participants themselves display their orientations to the phenomena.

The data were analysed by $\mathrm{SH}$, who was not present at the recordings and was unfamiliar with the participants in the study. In what follows, transcripts of the vocal production were produced using conventions modified from those common in CA, attributed to Gail Jefferson (2004; for conventions used here, see the Appendix). Where visual features judged relevant to the interactions are included in the analysis, supplementary video-stills are included. As such, readers will be in some, albeit limited, position to review the visual features described, and to judge the strength of the claims made. The gallery staff facilitators are referred to as FAC1 (male) and FAC2 (female). 


\section{Findings}

The data reported here are taken from the guided gallery tour of a woman, Suzan, with severe dementia. Conventional language was no longer possible for her. She was unable to mobilise without a wheelchair, and has since died. The inability of Suzan to speak, coupled with her compromised mobility, may appear to present CA with a challenge, as it removes much of what has long been central to CA endeavour, namely the sequential organisation of interlocutors' turns at talk in conversation. Work published by Charles Goodwin on interactions between an aphasic man, who is only able to utter three words, and members of his family, demonstrates how much the interlocutors are able to do with the limited range of utterances he can produce (Goodwin 1995). Elsewhere, Schegloff (2003) shows how a man diagnosed with a neurologically compromised communication disorder, even when he does not speak, participates in interaction in how he mobilises his body and gaze with reference to others' turns at talk. In our data, Suzan has none of these resources on which to draw, as we see in the following sequence (see Figure 2):

73 FAC1: $\operatorname{Suzan} \nearrow$

$74 \quad(7 \cdot 5)$

75 FAC1: all right $\nearrow$

$76 \quad(9 \cdot 7)$

77 FAC1: i think the idea is for people to sit on this little chair over 78 here in this corner】

Although Suzan is treated by the gallery facilitators as a co-participant in the conversations, there is nothing in the way of recognisable active contributions on her part. She does not produce anything in the way of communicative acts, but this absence is not treated as 'missing', or 'noticeably absent'. Within an ethnomethodologically inspired CA framework, 'noticeable absence' denotes when participants orient to something being missing. It is, in particular, linked to the notion of conditional relevance (Schegloff and Sacks 1973) where a communicative act makes a particular next action a relevant thing to produce by an interlocutor. For example, if a person greets someone, but receives no return greeting, this could be treated as noticeably absent, orienting to the social norm of the greeting adjacency pair. Where a lack of response is oriented to as being noticeably absent, participants may pursue a response (Pomerantz 1984), for instance by repeating or rephrasing an utterance. A non-response, or non-type-fitting response, may not however lead to an interlocutor being further pressured 


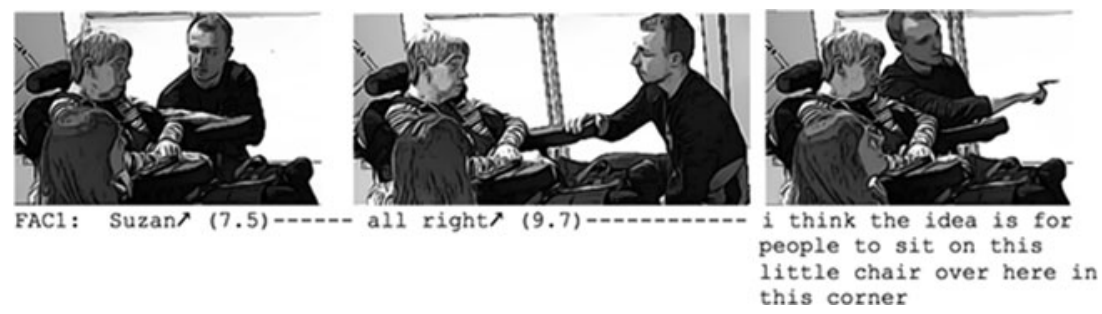

Figure 2. Stills from the video at lines $73^{-8}$.

for a conditionally relevant next. Where a person is not capable of providing responses, as in the case featured here in our data, speakers adapt their responses to the lack of displayed uptake from their interlocutors. We will turn to this now.

In the segment of the gallery tour analysed here, Suzan has been brought by two of the facilitators to an art installation (shown in Figure 1). Photographic portraits line a section of the wall, showing women of different eras. Viewers are invited to engage with the work by writing on cards and 'posting' these to their own mothers. The cards are scanned by the artist and subsequently displayed on a screen as part of the work. The artwork is explained to Suzan in the following excerpt (see Figure 3).

\section{Transcript I}

o1 FAC1: all these pictures on the wall are people-

o2 different people's mothers $\nearrow$

O3 (3.5)

o4 FAC1: and people write on these-

05 on these pad and paper $\searrow$

o6 (3.1)

o7 FAC1: a little memory about their mothers \

o8 and then they pop it in a little box down there $\searrow$

og (1.4)

10 FAC1: and then the artist comes in $\rightarrow$

11 SUZ: $\quad \mathrm{mn}(0.3) \mathrm{mn} \mathrm{mn} \searrow(0.3) \mathrm{mn}$

$12 \mathrm{FAC}_{1}$ : and puts it on the $\lceil\mathrm{se}\rceil$

$13 \mathrm{SUZ}:\lfloor\mathrm{mn}\rfloor \mathrm{mn} \mathrm{mn}$

$14 \quad(0.3)$

15 FAC1: up here $\rightarrow$ 
(a)

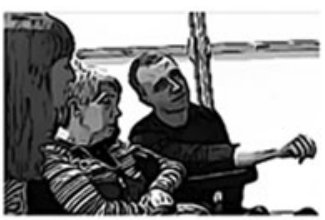

(b)

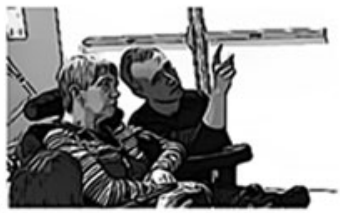

(c)

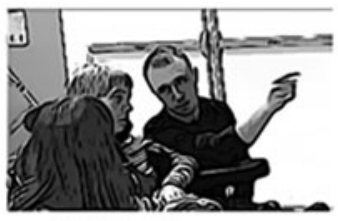

pictures

(e)

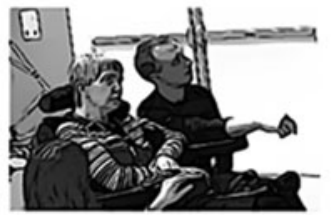

on the wall are people- different people's mothers $\nearrow$ (f)

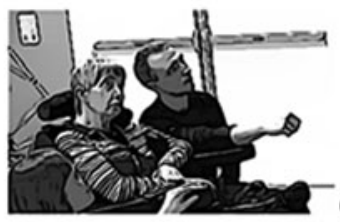

(g)

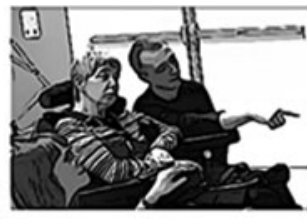

(goes and picks up pad) (3.5)-------- and people write on these- on these pad and paper) (h)

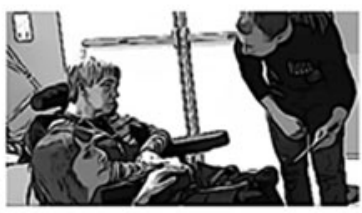

(3.1)

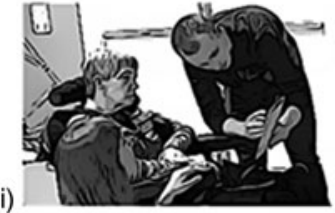

a little memory about their mothers $\searrow$

Figure 3. Stills from the video excerpt transcribed immediately above. Transcript 1, lines $01-07$.

An initial reading of transcript 1 highlights the sparsity of explicit contributions from Suzan to the unfolding activity. She sits in the wheelchair in silence, or at most produces a number of lexically void vocalisations, and audible in- and outbreaths. There is also nothing in her bodily movements which could readily be understood as performing gestural work ( $c f$. Schegloff 2003), nor any evidence from her co-participants that they treat her movements as such. In sum, the onus for carrying through the activity is on the facilitators. However, this does not mean that Suzan is excluded from the process of meaning-making, even though it is the facilitators who are in sole control of the direction and framing of the discussion. Indeed, we see evidence here of how Suzan is constructed as an active participant, how she becomes a central address in the meaning-laden interaction, in the ongoing talk about art through the skilful attention of the 


\section{Justine Schneider et al.}

facilitators. Within the context of an art gallery and its non-hierarchical setting, FAC1 and FAC2 are able to use turn-taking in conversation to orient to Suzan as a socially competent being, by treating her silences and vocalisations as fully formed responses to their talk. Neither of the speakers appears to treat Suzan as less than competent to participate. Within the context of the art gallery all three engage, without any external direction, in an interpretation and search for meaning through works of art. With access to the video data, we are better able to understand how the parties monitor one another's actions, and organise their contributions accordingly.

Heath and vom Lehn (2004) and Heath, vom Lehn and Hindmarsh (2001, 2002) show in their research that engagements with works of art cannot be fully grasped when focusing on the cognitive impact on a single viewer (Heath and vom Lehn 2004; Heath, vom Lehn and Hindmarsh 2001, 2002). They demonstrate that the search for meaning is not one-sided but is a collaborative effort with others: 'The relevant objects, and their momentary sense and significance, emerge moment by moment, within a complex negotiation through which the participants become momentarily aligned towards a specific exhibit' (Heath and vom Lehn 2004: 48).

The excerpt starts with FAC 1 turning his gaze from the artwork to Suzan (Figure 3, frames a and b), while FAC2 is moving from a standing position to being hunched down beside the wheelchair, with her gaze also oriented to Suzan. FAC 1 then initiates an account for the artwork, first with his gaze still focused on Suzan, while her eyes are closed. Then as she opens her eyes, he specifies the particular set of objects he is indicating. This is accompanied by a pointing gesture (frame $\mathrm{c}$ ), and a subsequent redirection of his gaze to the objects (frame $\mathrm{d}$ ). This establishes a new contextual configuration (Goodwin 2000), with both FAC1 and Suzan sharing in the viewing of the art installation, while FAC2 continues to monitor Suzan.

Again, we can see how both engage in a common search for meaning through works of art. With Suzan's compromised mobility restricting her ability to tilt her head far enough back to survey the whole piece, we see how she must raise her eyebrows in order to be able to look up at the photographs, which FAC1 is indicating with a series of pointing gestures. This visible act of looking displays to the others Suzan's attention to FAC1's account, and we see $\mathrm{FAC}_{2}$ responding to this by directing her gaze away from Suzan and to the artwork. As FAC1 reaches a turn relevant place (TRP) following 'different people's mothers', he suspends his finger point (frame e).

The position of the account and the rising turn-final intonation contour invite a response from Suzan, or alternatively from FAC2. However, we note 
that such a response is not forthcoming from either. The absence of response from FAC2 can be seen to index FAC1's turn as being directed at Suzan, rather than at FAC2 herself. There is, however, also no discernible response from Suzan either. Rather, in the $3 \cdot 5$-second pause we see how all three now survey the artwork in an almost collaborative fashion. Following the pause (frame f), FAG 1 continues with an increment to the account, detailing another component in the artwork, namely an invitation from the artist for visitors to contribute to it. The artwork addresses the participant not simply as a passive viewer, but as an active co-producer. He deploys a pointing gesture towards a notepad on a table in front of them (frame g), and notes how 'and people write on these- on these pad and paper \' (lines 04 and 05 ), with the connective 'and' indexing this as an increment to the earlier account. As he specifies the writing materials, he moves over to pick up a notepad, and holds it closer to Suzan for her to see. The turn is formatted with turn-final intonation, and presents another possible TRP. This invites uptake from his co-participants, but again there is none forthcoming. Momentarily, FAC 1 has his gaze directed at Suzan's face (frame h), where he is, however, able to see how her gaze has been fixated on the notepad. He then moves the pad closer to her, where he now shifts his own gaze to the object, so they are now both together looking at the notepad, and produces another increment (frame i). With another finger point he indicates a section of the page, continuing his account of what visitors have been invited to contribute. Again, here is another possible TRP (line o9), and again no explicit response from Suzan, and following another three-second pause, FAC1 builds on his prior turn to provide further information on how the artwork is organised.

Although the absence of uptake, e.g. in the form of an acknowledgement token or continuer, may in other participation frameworks lead to some form of repair initiation, or some pursuit of response, here we see that FAC1 treats Suzan as if she is in fact providing responses. By leaving silences where acknowledgement tokens, e.g. expressions of surprise or continuers, would normatively be found, and building on the silences as if responses has been forthcoming, FAC1 constructs Suzan as having produced appropriate responses, albeit without having been able to do so in a way that can be perceived by others. In a different context, Horton and Wohl (1956) showed that such 'as if' interactions create a para-social relationship that involves the participants to a degree that is no different from a typical social relationship.

In what follows, we see a similar pattern, but this time where Suzan's minimal vocalisations are treated as denoting particular social actions tied to the talk. 
1744 Justine Schneider et al.

\section{Transcript I continued}

10 FAC1: and then the artist comes in $\rightarrow$

11 SUZ: *mn (o.3) mn mn $\searrow(0.3) \mathrm{mn}^{*}$

12 FAC1: and puts it on the $\lceil\mathrm{se}\rceil$

$13 \mathrm{SUZ:}\lfloor$ :mn」mn mn*

$14 \quad(0.3)$

15 FAC1: up here $\rightarrow$

$16 \quad(1.2)$

17 FAC1: $\quad$ so that other people can read them $\rightarrow$

$18 \quad(0.5)$

19 SUZ: *mn: mn::: mn r:::*

$20 \quad(0.4)$

21 FAC1: ·h so there's lots of photographs

22 some quite new ones and some quite old ones $\nearrow$

$23 \quad(4.0)$

24 FAC1: some of them are from way before my time $\rightarrow$

25 SUZ: $\cdot$ hhhh hhhh

In line 10, FAC1 continues with his account of the art installation. It ends with continuing intonation, which projects that it has not reached completion. Towards the end of this, Suzan's hands start shaking with what looks like a series of spasms, which do not abate until line ${ }_{15}$, before occurring again between lines 19 and 24. The spasm is accompanied by a series of vocalisations from Suzan, which appear to express some discomfort, and she closes her eyes for the duration too. We note how FAC1 is sensitive to Suzan's vocal and bodily visual displays. He suspends the turn initiated in line 10 until Suzan's vocalisations appear to subside (line 11), and only then picks up where he left off. In line 12, he again suspends the progression of his turn, at a grammatically incomplete point, as Suzan produces a number of vocalisations (line 13), and he picks it up again, having left a brief pause, in line 15 .

What FAC1 achieves by organising his talk around Suzan's displays, is to incorporate her vocalisations into the turn-taking as the kinds of contribution one might expect to find at these sequential positions. These nonlexical vocalisations (e.g. lines 11, 13 and 19) are not simply treated as displays of discomfort, as erratic behaviour, but rather as valid contributions embedded in a sequential structure. FAC1 interrupts his talk (lines 10 and lines 12) or even holds off till after a moment of silence (lines 14 
and 20) before continuing with his explanation. As a result, Suzan's vocalisations or her silence are not talked over, but rather she is spoken with and is oriented to as actively contributing. Her vocalisations and her silence are therefore not treated as 'non-communication', but as meaningful contributions in this part of this interaction (Luhman 1994). Again, turning to the video data, we note the sensitivity with which FAC1 co-ordinates this, as illustrated in Figure 4 .

As $\mathrm{FAC}_{1}$ reaches the TRP at the end of line 17 , he turns his gaze to Suzan, inviting a response. At this point, she endures another spasm in her hands, and produces a series of vocalisations. FAC1's gaze conduct is interesting here. He monitors Suzan for the first vocalisations (Figure 4, frame b), then shifts his gaze back to the artwork as she continues with her vocalisations (frame c), before returning his gaze to her again (frame $d$ ). By turning his gaze to the artwork during her murmurings and surveying the piece as she produces these displays could be seen as him treating her voicings as articulating something about the artwork, something that makes it relevant for him to direct his attention there. He returns the gaze to her subsequently, and after holding off for a short moment, he continues with his account, while turning his gaze back to the artwork (frame e). The sequence shows how FAC1 closely monitors Suzan, leaving her space to produce her vocalisations. It also suggests that how he acts in response to the displays indexes her murmurings as social actions, which come with normative expectations for how to act in accordance. It therefore treats Suzan as a socially engaged person in the activity, rather than a passive vessel.

\section{Discussion}

Whereas the linguistic memory (recognition and expression of words) is notoriously unreliable in dementia, meaning-making is an activity that appears to persist, at least as long as a human being can take part in joint activities (Hughes, Louw and Sabat 2005). The facilitators worked empathically to include Suzan in what appeared to be successful communicative acts during the gallery tour, examples of which are given here. We have sought to demonstrate that, at the very least, the facilitators enabled Suzan to have agency in communication. We cannot infer that Suzan's sounds are proxies for recognisable words, nor that her vocalisations carry particular intentions. However, the analysis illustrates how murmurings and visible displays of attention on Suzan's part are effectively treated as part of a meaningful interaction by the gallery facilitator. Video captures even the most indistinct speech and almost-imperceptible actions. Our interpretation here is that such behaviours can be used as proxies for the types of utterance that 
(a)

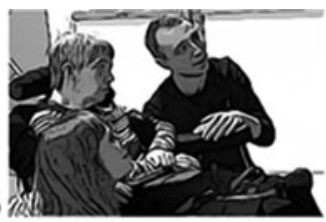

FAC1 (b)

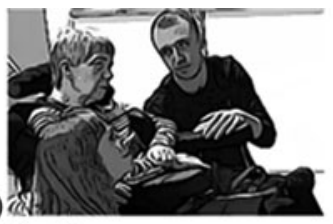

$(0.5)--$

SUZ mn: mn: :

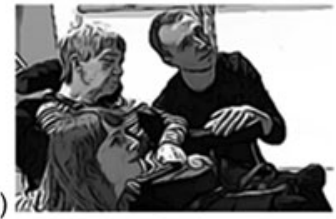

(d)

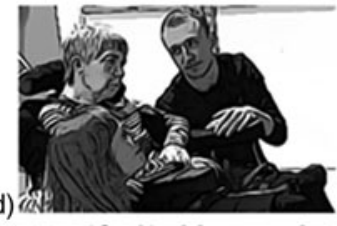

(e) $r::$ :

SUZ $\mathrm{mn}$

.4) $\cdot$ hh so there's lots of photographs

Figure 4. Illustrates approach taken by FAC1 to enable communication by the subject of the research. Transcript 1 , lines 1 1-21.

would normally be found at particular sequential positions in the unfolding turn-taking practices within a conversational interaction. As such, the facilitators were able to constitute (or re-constitute) the person with dementia as being an active member in the dialogue (Goodwin 2000).

The guide was faced with a dilemma: to treat Suzan's spasms as an indication of discomfort and discontinue the interaction, or to accept them as an ordinary aspect of Suzan's way of being and carry on, which is what he did. Suzan's husband later confirmed that the latter was true, but it would have been desirable to verify this independently, for instance by observing her over a much longer period of time. While there remains the possibility that Suzan's subjective experience was not comfortable at some point in the viewing, her level of alertness was markedly greater than usual throughout the gallery tour, by contrast with her tendency to appear to be dozing in her chair. A limitation of the study is that we did not debrief Suzan's husband shortly after the gallery experience-perhaps the following day - to ask how the night had passed. On reviewing the present paper, one year later, Suzan's husband volunteered the following observations:

[her] reactions during the gallery session all seemed to be quite normal regarding eye/facial expressions and hand movement. Indications of distress were not displayed during the session and it would be difficult to assess this when [Suzan] was at home in her normal environment.

Furthermore, he informed us that Suzan

had always enjoyed visiting art galleries, museums, National Trust properties/ gardens all over England before the onset of dementia. That is why I carried on 
with visits throughout her illness. In the latter years when communication had stopped I carried on with the visits knowing that she enjoyed the experiences but it was difficult to assess the degree of pleasure it gave her.

A criticism of the study may be that there is no direct evidence that Suzan is making any interaction with the art; perhaps she is simply reacting to social stimulation. Nonetheless, we hope to have demonstrated, using this methodological approach, that Suzan, despite her motor and linguistic disabilities, has participated in the interaction with the facilitator. We have presented evidence of her interaction in the flow of the conversation and the sequence of movements around her, but it is important not to reject the possibility that Suzan is indifferent to the works of art and is simply responding to the facilitators. How relevant is the art, then? It provided a focus for the interaction to take place. It determined the place in the gallery where Suzan and her escorts came to a halt, and it provided the basis for the explanatory comments and gestures of the facilitator. We suggest that the triad, consisting of the work itself, the facilitator and Suzan, is relevant, indeed crucial, for the success of the interaction. In terms of Gibson's theory of affordances (Gibson 1977), the art works afford the participants an opportunity for meaning-making. For Suzan, this facilitates a successful communicative act. Writing about the accomplishment by people with dementia of successful communicative acts, Kitwood said:

Confusion and disorder within the psyche was met with order and stability in the social world: hope was sustained. It is the repetition of this experience, we may hypothesize, that can establish well-being even in the face of severe cognitive impairment. (Kitwood 1993: 66)

If our analysis that successful communication took place is accepted, then according to this perspective, it was beneficial for Suzan. Therefore, we offer the findings from this case study to support previous evidence of benefits to people with dementia from viewing art (Young et al. 2015)

\section{Conclusion}

We have demonstrated the feasibility of video-analysis in studying communication in severe dementia. We have also sought here to advance theory in this context. Kitwood and Bredin's person-centred care approach, which has underpinned practice and informed policy for a quarter of a century, stresses the social roles of people despite their dementia, making the objectives of care to promote self-esteem, agency, social confidence and hope in individuals with a diagnosis of dementia. Yet in most cases 'care' is still the 


\section{Justine Schneider et al.}

aim and purpose of interactions, with adverse connotations of dependence and disempowerment. The second contribution of this study is that it changes the context of interaction with a person with dementia, and demonstrates positive social interactions in a public space that is designed for culture or leisure, rather than for clinical interventions or 'care'. Given the growing numbers of community-dwelling individuals with dementia, their social inclusion is already regarded as a high policy priority. The 'dementia-friendly' accolade is increasingly used for communities, public spaces and also arts venues (Allen et al. 2015). Art galleries offer a non-hierarchical, non-judgemental environment to which people with dementia even those whose communication is severely impaired-can have access with minimal adaptations (MacPherson et al. 20o9). Of course, attitudinal barriers on all sides may need to be addressed, and front of house personnel may need suitable training and preparation.

Our key finding here that communication in itself can be facilitated in a gallery context merits further research. Given the importance of successful communicative acts as beneficial ends in themselves for people with dementia, we have shown that talk around art generates this kind of affirming conversation. It is therefore possible that facilitated access to galleries and museums could help to engage and stimulate people with dementia, including those whose speech is impaired, contrary to many preconceptions. Questions for further research include whether people whose cognition is impaired find themselves less disabled in a gallery environment than in other social settings, such as pubs, which require linguistic communication, or cinemas, where one needs sufficient memory to follow a narrative. But first, further empirical evidence is needed to test the arguments which we assemble here around the inherent benefits of successful communicative acts in severe dementia. An obvious direction would be to utilise physiological measures together with video-analysis to explore the subjective experience of individuals who cannot voice their opinions.

\section{Acknowledgements}

We would like to thank the family of our participant with dementia for their commitment to generating new knowledge about dementia. Neil Walker allowed us access to the gallery and Hannah Stoddart project managed the private viewings. This study could not have been conducted without the skilled support of the gallery guides, Wayne Marriott and Liz Hay Lewis, who facilitated the viewings. We are also extremely grateful to Laura Carone and Elizabeth Stroud who helped with the filming. Linguistic Profiling for Professionals at the University of Nottingham supported Spencer Hazel's contribution to the paper. Alzheimer's Research UK funded the research through a pump-priming award. A positive ethical opinion 
was given by the School of Sociology \& Social Policy, University of Nottingham Ethics Committee (Reference $5^{8 / 1} 5^{-16 / S}$ ).

\section{Appendix}

\section{Transcription conventions}

The transcription conventions are based on those developed by Gail Jefferson (e.g. Jefferson 2004). Some are used in modified form for use in the CLAN software tool (MacWhinney and Wagner 2010).

$\begin{array}{ll}\text { Identifier } & \text { TEA: } \\ \text { Pause } & (\mathrm{o.2}) \\ \text { Overlap markers top } & \\ \text { Overlap markers bottom } & \backslash \\ \text { Intonation rising } & \nearrow \\ \text { Intonation continuing } & \rightarrow \\ \text { Intonation falling } & \searrow \\ \text { Pitch shift } & \uparrow \\ \text { Latched turns } & \approx \\ \text { Creaky voice } & *_{\text {creak* }} \\ \text { Inbreath } & \text { hhhh }\end{array}$

\section{References}

Allen, P., Brown, A., Camic, P., Cutler, D., Harvey, L., Parsons, M., Sweeney, R., Ward, E. and Zeilig, H. 2015. Becoming a Dementia-friendly Arts Venue: A Practical Guide. Alzheimer's Society, London.

Beard, R. L. 2012. Art therapies and dementia care: a systematic review. Dementia: International Journal of Social Research and Practice, 1 1, 5, 633-56.

Bourdieu, P. 1992. Rules of Art. Stanford University Press, Stanford, California.

Bürger, P. 1984. The Theory of the Avant-garde. University of Minnesota, Minneapolis, Minnesota.

Camic, P. M., Tischler, V. and Pearman, C. H. 2014. Viewing and making art together: a multi-session art-gallery-based intervention for people with dementia and their carers. Aging and Mental Health, 18, 2, 161-8.

Chatwin, J. 2014. Conversation analysis as a method for investigating interaction in care home environments. Dementia: International Journal of Social Research and Practice, 13, 6, 737-46.

Cowl, A. L. and Gaugler, J. E. 2014. Efficacy of creative arts therapy in treatment of Alzheimer's Disease and dementia: a systematic literature review. Activities, Adaptation E' Aging, 38, 4, 281-330.

Department of Health 201 2. Prime Minister's Challenge on Dementia: Delivering Major Improvements in Dementia Care and Research by 2015. Department of Health, London.

Dewing, J. 2007. Participatory research: a method for process consent with persons who have dementia. Dementia: International Journal of Social Research and Practice, 6 , $1,11-25$. 
Dooley, J., Bailey, C. and McCabe, R. 2015. Communication in healthcare interactions in dementia: a systematic review of observational studies. International Psychogeriatrics, 27, 8, $1277-300$.

Eekelaar, C., Camic, P. M. and Springham, N. 2012. Art galleries, episodic memory and verbal fluency in dementia: an exploratory study. Psychology of Aesthetics Creativity and the Arts, 6, 3, 262-72.

Etkind, S. N., Bone, A. E., Gomes, B., Lovell, N., Evans, C. J., Higginson, I.J. and Murtagh, F.E. M. 2017. How many people will need palliative care in 2040? Past trends, future projections and implications for services. BMC Medicine, 15, $1,102$.

Flatt, J. D., Liptak, A., Oakley, M. A., Gogan, J., Varner, T. and Lingler, J. H. 2015. Subjective experiences of an art museum engagement activity for persons with early-stage Alzheimer's Disease and their family caregivers. American Journal of Alzheimers Disease and Other Dementias, 30, 4, 380-9.

Gibson, J.J. 1977. The theory of affordances. In Shaw, R. and Bransford, J. (eds), Perceiving, Acting, and Knowing. Toward an Ecological Psychology. Lawrence Erlbaum Associates, Hillsdale, New Jersey, 67-82.

Goodwin, C. 1995. The negotiation of coherence within conversation. In Gernsbacher, M. A. and Givón, T. (eds). Coherence in Spontaneous Text. Amsterdam: John Benjamin, $117-37$.

Goodwin, C. 200o. Action and embodiment within situated human interaction. Journal of Pragmatics, 32, 10, 1489-522.

Hansebo, G. and Kihlgren, M. 2002. Carers' interactions with patients suffering from severe dementia: a difficult balance to facilitate mutual togetherness. Journal of Clinical Nursing, 1 1, 2, 225-36.

Hazel, S., Mortensen, K. and Rasmussen, G. 2014. Introduction, special issue: 'A body of resources - CA studies of social conduct'. Journal of Pragmatics, $\mathbf{6}_{5}, \mathbf{1}-9$.

Heath, C. and Hindmarsh, J. 2002. Video, ethnography and situated conduct. In May, T. (ed.), Qualitative Research in Action. Sage, London, 99-121.

Heath, C. and vom Lehn, D. 2004. Configuring reception: (dis-) regarding the 'spectator' in museums and galleries. Theory, Culture EF Society, 2 1, 6, 43-65.

Heath, C., vom Lehn, D. and Hindmarsh, J. 2001. Exhibiting interaction: conduct and collaboration in museums and galleries. Symbolic Interaction, 24, 2, 189-216.

Heath, C., vom Lehn, D. and Hindmarsh, J. 2002. Video-based filed studies in museums and galleries. Visitor Studies Today!, 5, 3, $15^{-23}$.

Horton, D. and Wohl, R. $195^{6}$. Mass communication and para-social interaction: observation on intimacy at a distance. Psychiatry, 19, 3, $215^{-29}$.

Hughes, J., Louw, S. and Sabat, S. 2005. Dementia: Mind, Meaning, and the Person. Oxford University Press, Oxford.

Jefferson, G. 2004. Glossary of transcript symbols with an introduction. In Lerner, G. (ed.), Conversation Analysis: Studies from the First Generation. Amsterdam: John Benjamin, 13-31.

Kitwood, T. 1993. Towards a theory of dementia care - the interpersonal process. Ageing and Society, 13, $5^{1-67}$.

Kitwood, T. and Bredin, K. 1992. Towards a theory of dementia care: personhood and well-being. Ageing Eo Society, 1 2, 3, 269-87.

Knoblauch, H. 2006. Videography. Focused ethnography and video analysis. In Knoblauch, H., Schnettler, B. and Raab, J. (eds), Video Analysis: Methodology and Methods: Qualitative Audiovisual Data Analysis in Sociology. Peter Lang, Frankfurt, Germany, 69-84.

Lindholm, C. 2008. Laughter, communication problems and dementia. Communication $\mathcal{E}^{2}$ Medicine, 5, 1, 3-14. 
Lindholm, C. and Wray, A. 2011 . Proverbs and formulaic sequences in the language of elderly people with dementia. Dementia: The International Journal of Social Research and Practice, 10, 3, 1-21.

Luhman, N. 1994. Speaking and silence. New German Critique, 61, $25^{-37 .}$

MacPherson, S., Bird, M., Anderson, K., Davis, T. and Blair, A. 2009. An art gallery access programme for people with dementia: 'you do it for the moment'. Aging $\mathcal{E}^{\circ}$ Mental Health, 13, 5, 744-52.

MacWhinney, B. and Wagner, J. 2010. Transcribing, searching and data sharing: the CLAN software and the TalkBank data repository. Gespraechsforschung, 11, 154-73.

Mittelman, M. and Epstein, C. 2009. Meet Me: Making Art Accessible for People with Dementia. Museum of Modern, New York.

Pomerantz, A. 1985. Agreeing and disagreeing with assessments: some features of preferred/dispreferred turn shapes. In Maxwell Atkinson, J. and Heritage, J. (eds), Structures of Social Action: Studies in Conversation Analysis. Cambridge, UK: Cambridge University Press, 57-101.

Sabat, S. R. and Harré, R. 1992. The construction and deconstruction of self in Alzheimer's Disease. Ageing Eீ Society, 1 2, 4, 443-61.

Saunders, P. A. 1998. 'My brain's on strike': the construction of identity through memory accounts by dementia patients. Research on Aging, 20, 1, 65-9o.

Schegloff, E. 2003. Conversation analysis and communication disorders. In Goodwin, C. (ed.), Conversation and Brain Damage. Oxford University Press, Oxford, 21-55.

Schegloff, E. A. and Sacks, H. 1973. Opening up closings. Semiotica, 8, 4, 289-327.

Wasilewski, T.P. and Kachaniuk, H. 2016. Speech disturbances in Alzheimer's Disease. Neuropsychiatry $\mathcal{E}$ Neuropsychology, 1 1, 3, 93-98.

Weir, H. 2010. You don't have to like them. Art, Tate Modern and learning. Applied Arts and Health, 1, 1, 99-110.

Young, R., Tischler, V., Hulbert, S. and Camic, P. M. 2015. The impact of viewing and making art on verbal fluency and memory in people with dementia in an art gallery setting. Psychology of Aesthetics Creativity and the Arts, 9, 4, 368-75.

Accepted 26 January 2018 ; first published online Iо April 2018

Address for correspondence:

Justine Schneider,

School of Sociology \& Social Policy,

University Park,

Nottingham NG7 2RD, UK

E-mail: Justine.Schneider@nottingham.ac.uk 